\title{
Early Maladaptive Schemas and Academic Procrastination in Students: The Mediating Role of Perfectionism
}

\author{
Mohammad Setayeshi Azhari ${ }^{1}$ \\ ${ }^{1}$ University of Tabriz, Tabriz, Iran \\ Correspondence: Mohammad Setayeshi Azhari, University of Tabriz, Tabriz, Iran. E-mail: \\ Setayeshi_m@yahoo.com
}

Received: June 18, 2017

Accepted: July 3, 2017

Online Published: November 20, 2017

doi:10.5539/ijps.v9n4p76

URL: http://doi.org/10.5539/ijps.v9n4p76

\begin{abstract}
Studies indicate that many students engage in procrastination, thus in this study the aim was to examine the structural relationship of early maladaptive schemas and academic procrastination with the mediating role of the perfectionism in students. The participants included 281 high school students (143 male, 138 female) that were chose by multistage cluster sampling method. Solomon and Rothblum's academic procrastination scale with the Cronbach alpha coefficient 0.81 and Young early maladaptive schema questionnaire with the Cronbach alpha coefficient 0.93, and Positive and Negative Perfectionism questionnaire with the Cronbach alpha coefficient 0.86 were administered. Structural Equation Modeling (SEM) and Sobel tests were conducted to explore direct and indirect pathways of study's model respectively. Results showed that early maladaptive schemas and academic procrastination are antecedents and consequences of perfectionism in students respectively. The results indicated that perfectionism has a significant mediating role on the relationship between early maladaptive schemas and academic procrastination. The findings of this study could help school counselors, education psychologist, and teachers to reduce student's procrastination and academic problems.
\end{abstract}

Keywords: early maladaptive schemas, perfectionism, academic procrastination

\section{Introduction}

Solomon and Rathblum (1984) defined academic procrastination as postponing academic tasks and consequently feeling discomfort. Procrastination, as a serious problem in schools and one of the most prevalent problematic behavior, in a way that estimates indicate that approximately over $70 \%$ students involve procrastinators (Schouwenburg, Lay, Pychyl, \& Ferrari, 2004; Ellis \& Knaus, 1977). Several studies has showed that procrastination can lead to low student's academic achievement (Kim \& Seo, 2016), consequently lowering their life satisfaction, psychological well-being, and coping (Trucchia, Lucchese, Enders, \& Fernandez, 2013; Crede, Wirthwein, McElvany, \& Steinmayr). Thus, it's important that being aware of procrastination effects and their role in student's life to prevent low academic achievement, life satisfaction, psychological well-being, and coping. Among the numerous factors in explaining academic procrastination, anxiety (Onwuegbuzie, 2004), stress (Kandemir, 2014; Rahardjo, Juneman, \& Setiani, 2013), self-efficacy (Klassen, Krawchuk, \& Rajani, 2008; Odaci, 2011; Hajiloo, 2014; Howell, Watson, Powell, \& Buro, 2006) frequently used to explain academic procrastination. In this regard Lowinger, Kou, Song, Mahadevan, Kim, Liao, Chang, Kwon, Han (2016) conducted a study on Asian International students to predict the procrastination, this study showed that collective coping style, avoidant coping style, academic self-efficacy, and English language proficiency could predict the academic procrastination. As result procrastination has consequences and also this construct has antecedents.

One of the psychological factors that is antecedents of procrastination is early maladaptive schema. Young, Klosko, and Weishaar (1950) "hypothesized that some of these schemas-especially schemas that develop primarily as a result of toxic childhood experiences - might be at the core of personality disorders, milder characterological problems, and many chronic Axis I disorders". Classification of EMSs resulted in five higher order schema domain and each domain consist of own schema, disconnection and rejection domain included these schemas; abandonment/instability, mistrust/abuse, emotional deprivation, defectiveness/shame, and social isolation/alienation. Impaired autonomy and performance domain included dependence/incompetence, vulnerability to harm or illness, enmeshment/undeveloped self, and failure. Impaired limits domain included these schemas; entitlement/grandiosity, and insufficient self-control/self-discipline. Other-directedness domain 
consist of these schemas; subjugation, self-sacrifice, and approval-seeking/recognition-seeking. Over vigilance and inhibition domain included these schemas; negativity/pessimism, emotional inhibition, unrelenting standards/hypocriticalness, and punitivness (Young, Klosko, \& Weishaar, 1950). Young et al. (1950) believed EMSs have a wide effect on different aspects of life and personality. Procrastinators have self-talk with themselves such as "I can't do it; I can't handle it", "I can't do it by myself", and "I messed it up last time" (Basco, 2010). According to Beck (1995) such self-talk drive early life experience.

Research has identified academic procrastination, low self-esteem, depression, perfectionism, and anxiety are results of early life experiences and early maladaptive schemas. Depression and body image has been associated with early maladaptive schemas (failure, emotional deprivation, abandonment/instability) (Renner, lobbestael, Peeters, Arntz, \& Huibers, 2012; Mojallal, Khosrojavid, Pakzad, \& Ghanbari, 2014). Parenting which experienced in early childhood can has effect on individuals' life. Pschyl, Coplan, and reid (2002) in a study showed that parenting style, self-worth, and gender can predict to the procrastination, a similar study showed that acceptance-involvement, and psychological autonomy-granting styles can negatively predict to the academic procrastination (Zakeri, Esfahani, \& Razmjoee, 2013). Several studies have previously focus on psychological factors to investigating academic achievement. Isanejad et al. (2012) in a compared study revealed that early maladaptive schemas were different in two groups of high academic anxiety and low academic anxiety and those who experience high levels of academic anxiety report higher levels of early maladaptive schemes. Heidary, Rudbari, and Isanezhad (2012) expressed that "there is a significant difference between individuals with high academic stress and low academic stress in the early maladaptive schemes" it seems that EMSs play an important role in academic performance and achievement. Research findings confirm that internalizing symptomatology has been linked academic achievement (Weidman et al., 2015), high depression and anxiety during one hundred and thirty adolescents predicting lower academic achievement at the beginning of a school year. In addition Malinauskiene, Vosylis, and Zukauskiene (2001) in a longitudinal study showed that there is a relationships between internalizing and externalizing problem behavior syndromes and academic achievement, as well as Maurizi et al. (2013) in their study revealed that the social relationships play a moderating role in the relationship between depressive symptoms and academic achievement.

Other antecedents of academic procrastination is perfectionism. Perfectionism, in psychology, described as negative construct which involves demanding standards for flawlessness performance Frost et al. (1990) expressed that these demanding standards are accompanied by tendencies for overly critical evaluations of themselves. Thus, it's obvious (clear) that these demanding standards for flawlessness performance caused procrastination, in the other hand perfectionism has been linked with procrastination (Shafran, Egen, \& Wade, 2010). A study by Jadidi, Mohammadkhani, and Tajrishi (2011) revealed that there is positive relationship between perfectionism and academic achievement. Capan (2010) founded that Self-oriented perfectionist personality trait associated with academic procrastination and life satisfaction. According to Burnam, Komarraju, Hamel and Nadler (2014) perfectionism can predict to the various type of procrastination (exam preparation, writing papers, and completing reading assignments), Kiral (2015) founded that locus of control associated with perfectionism. Karner-Hu uleac (2014) examined the relationship between Perfectionism and self-handicapping in adult education, the result indicated that there is a negative and significant relationship between perfectionism and academic achievement also self-handicapping was positively related to perfectionism, some research showed that perfectionism can predict to the well-being, a study by Lan and Ju (2015) noted that perfectionism, achievement motivation and attributional style can predict to the well-being in Chinese university students. Handley, Egan, Kane, and Kane (2015) in experimental study showed that cognitive behavior therapy has a great effect on reducing perfectionism, symptoms of depression, eating disorders, social anxiety, anxiety sensitivity and rumination, as well as increasing self-esteem and quality of life.

The aim of this study is to test the concurrent mediation effects of negative procrastination on the relationship between early maladaptive schemas and academic procrastination. Based on the preceding rationale and the available literature that has shown the relationships of early maladaptive schemas with academic procrastination, of negative perfectionism with academic procrastination, it was predicted in this study that negative perfectionism might act as a mediator on the impact of early maladaptive schemas on academic procrastination and also most of the research was conducted in Western culture. Testing the mediation models in an Asian country to resolve this limitation would provide evidence of external validity, also pervious study gave less importance to the role of the early life experience that the procrastination may has the relationship with early life experiences. Therefore, based on the previous studies, we proposed a model concerning the mediator role of negative perfectionism in the relationship between early maladaptive schemas and academic procrastination, as 
presented in Figure 1. So, it is hypothesized that negative perfectionism will mediate the associations between early maladaptive schema and academic procrastination in a sample of Iranian high school students.

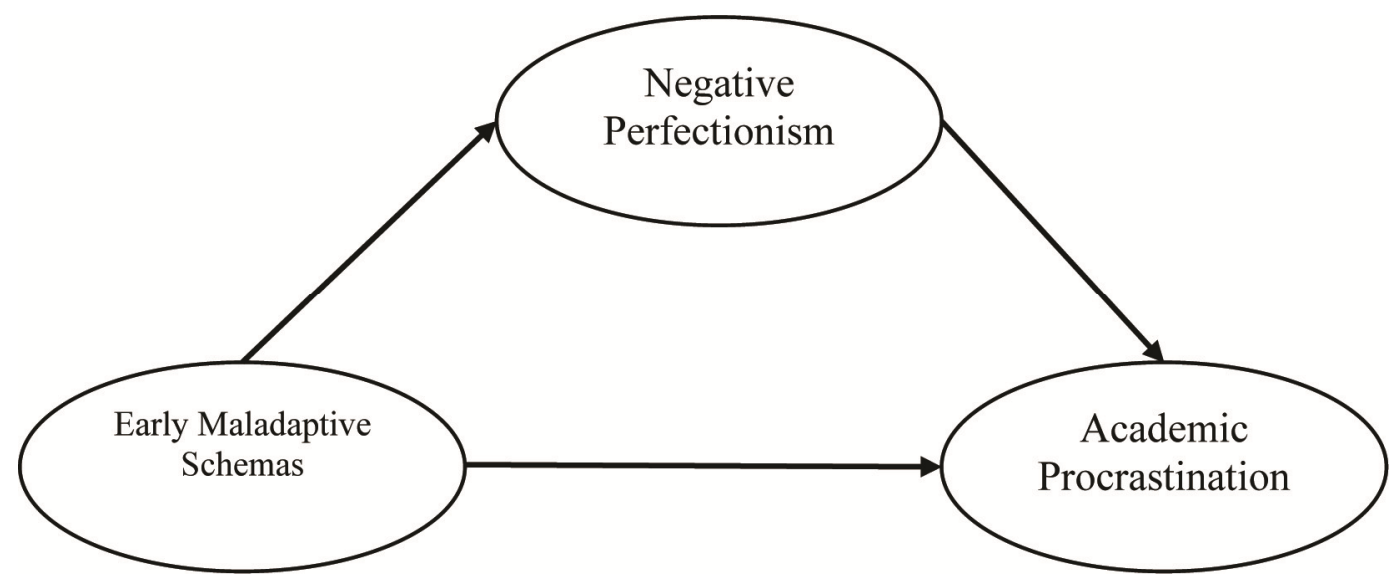

Figure 1. The hypothesized model concerning the mediator of negative perfectionism in the relationship of early maladaptive schemas with academic procrastination

\section{Method}

The participants included 281 high school students with a mean age of 16 years $(\mathrm{SD}=.65)$ during the 2015-2016 academic year. The two genders were equally represented in the sample, which included 143 males $(50.8 \%)$ and 138 females (49.1\%). The participants were randomly selected from different schools in areas of four educational districts in Qom. Each school has about 300 students.

\subsection{Young Early Maladaptive Schema Questionnaire}

EMSs scale (short form), is a self-report measure of early maladaptive schemas. The EMSs is comprised 75 items that measure 15 subscales of EMSs;

1) abandonment/instability;

2) dependence/incompetence;

3) defectiveness/shame;

4) emotional deprivation;

5) overcontrol;

6) enmeshment/undeveloped self;

7) entitlement/self-centeredness;

8) failure;

9) insufficient self-control/self-discipline;

10) mistrust/abuse;

11) subjugation;

12) social isolation/alienation;

13) self-sacrifice;

14) unrelenting standards/hypercriticalness

15) vulnerability to danger/random events.

Participants rate their level of agreement with each statement on a 6-point Likert scale ranging from $1=$ "completely untrue of me" 6="describes me perfectly". Nikmanesh, Kazemi, Khosravi, and Bohonar (2015) supported internal consistency (Cronbach's alpha $=.83$ ), and test-retest reliability $(\mathrm{r}=.82)$ of the scale. In this study, for the EMSs scale Cronbach's $\alpha=.93$. Cronbach's alpha for each schema was calculated in this study; abandonment/instability it was 0.82 , dependence/incompetence 0.75 , defectiveness/shame 0.64 , emotional 
deprivation 0.77 , overcontrol 0.82 , enmeshment/undeveloped 0.82 , entitlement/self-centeredness 0.86 , failure 0.81 , insufficient selfcontrol/self-discipline 0.63 , mistrust/abuse 0.71 , subjugation 0.78 , social isolation/alienation 0.72 , self-sacrifice 0.88 , unrelenting standards 0.68 , vulnerability to harm of illness, 0.74 .

\subsection{Academic Procrastination Questionnaire}

In this questionnaire 27 items were developed by Solomon and Rathblum in 1984. Each question is scored on a scale point $(1=$ mot at all a problem to $5=$ always a problem). The Cronbach alpha coefficient for all 27 items was .64 (Solomon \& Rathblum, 1984) in this study, the reliability coefficient of the scale was calculated as .86

\subsection{Positive and Negative Perfectionism Questionnaire}

PNP questionnaire created in 1995 by Terry Short et al. that is a self-report instrument. It is designed to assess positive perfectionism and negative perfectionism. Responses range from 1 (strongly disagree) to 5 (strongly agree). In our sample, the PNP scale showed a Cronbach's Alphas of 0.65. Similar results were described by Burns and Fedewa (2005) who reported a Cronbach's Alphas for the Positive and Negative Perfectionism Scale 0.86 . In the current sample, PP $(\mathrm{a}=.79)$ and NP $(\mathrm{a}=.74)$ showed high internal consistency. The Cronbach alpha coefficient for all 40 items was 0.86 , in this study

\subsection{Procedure}

Two hundred and eighty one participants answered the questionnaires in classroom environment (143 males and 136 females). All participants were informed of the purpose of this study. Questionnaires took approximately 20 min to complete. The aim of the study is to investigate mediation effects of perfectionism and procrastination on the relationship between early maladaptive schemas and academic achievement. Sobel test was conducted to explore mediation effects of perfectionism and procrastination on the relationship between early maladaptive schemas and academic achievement. The data has been analyzed using the quantitative program SPPS

\section{Results}

Mean, standard deviations, and the ranges of early maladaptive schema, negative perfectionism, and academic procrastination are presented in Table 1 .

Table 1. Descriptive statistics early maladaptive schema, negative perfectionism, academic procrastination

\begin{tabular}{lcccc}
\hline & $\mathrm{M}$ & $\mathrm{SD}$ & $\mathrm{Min}$ & $\mathrm{Max}$ \\
\hline Early maladaptive schemas & 31.53 & 11.59 & 15 & 75 \\
Negative perfectionism & 66.61 & 11.68 & 22 & 91 \\
Academic procrastination & 38.12 & 9.12 & 11 & 64 \\
\hline
\end{tabular}
$\mathrm{N}=281$.

Correlations among study variables are presented in Table 2. The correlation analysis showed that early maladaptive schemas was significantly and positively correlated with negative perfectionism $(\mathrm{r}=.43, \mathrm{p}<.01)$ and academic procrastination $(\mathrm{r}=.57, \mathrm{p}<.01)$. Negative perfectionism was significantly and positively associated with academic procrastination $(\mathrm{r}=.54, \mathrm{p}<.01)$.

Table 2. Correlation among early maladaptive schemas, negative perfectionism, and academic procrastination

\begin{tabular}{lccc}
\hline & $\begin{array}{r}\text { Early maladaptive } \\
\text { schemas }\end{array}$ & $\begin{array}{c}\text { Negative } \\
\text { perfectionism }\end{array}$ & $\begin{array}{c}\text { Academic } \\
\text { procrastination }\end{array}$ \\
\hline $\begin{array}{l}\text { Early maladaptive } \\
\text { schemas }\end{array}$ & $0.19^{* *}$ & $0.19^{* *}$ & $0.39^{* *}$ \\
$\begin{array}{l}\text { Negative perfectionism } \\
\begin{array}{l}\text { Academic } \\
\text { procrastination }\end{array}\end{array}$ & $0.39^{* *}$ & $0.22^{* *}$ & $0.22^{* *}$ \\
\hline
\end{tabular}

The direct path coefficient from early maladaptive schemas to academic achievement in the absence of mediators (negative perfectionism) was significant $(\beta=.47, \mathrm{~S} . \mathrm{E}=.08, \mathrm{p}<0.01)$, which supported in Figure 2. This model 
include a mediator variable, negative perfectionism between early maladaptive schemas and academic achievement. This model being showed a good fit to the data.

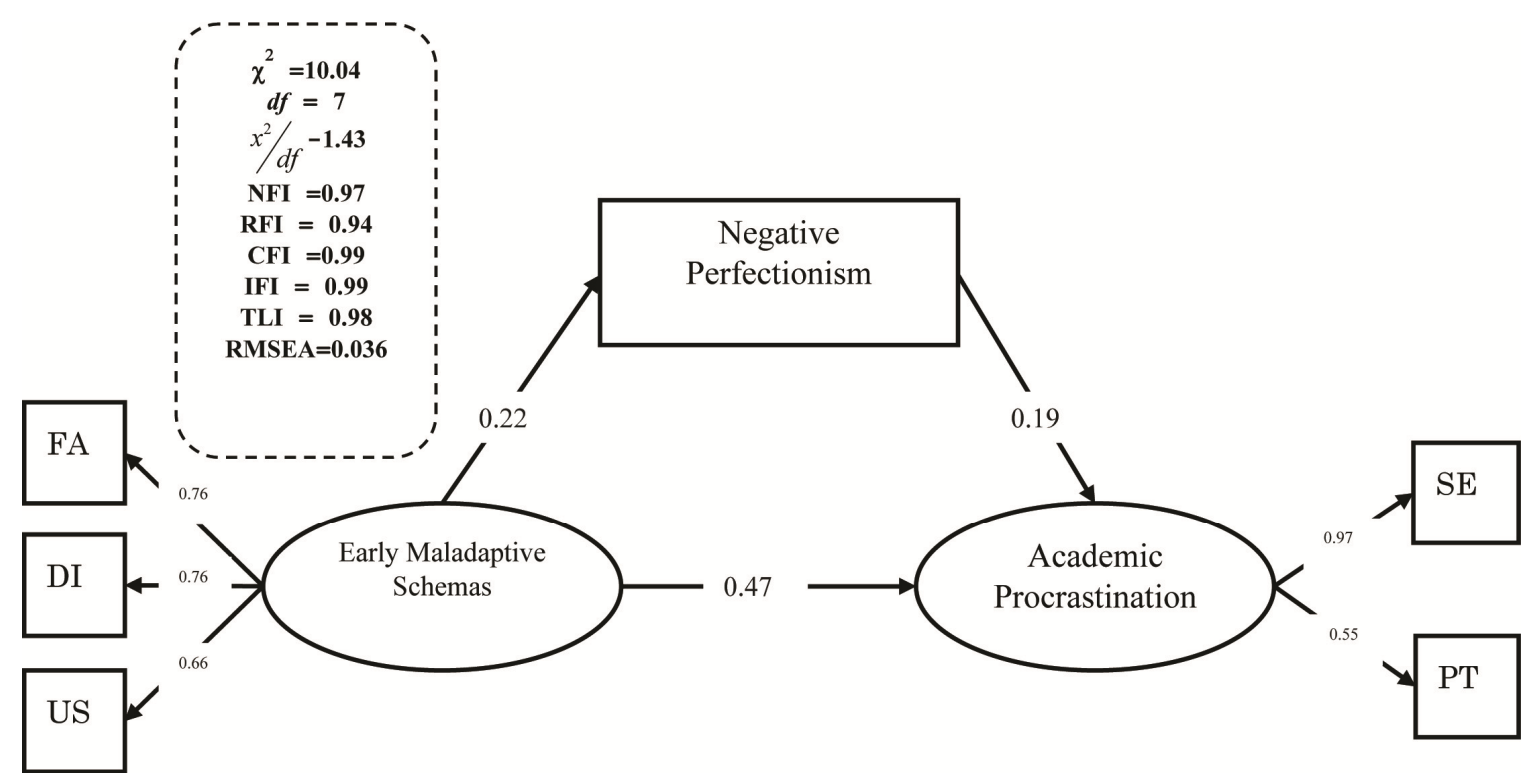

Figure 2. The structural equation model regarding the mediating effects of negative perfectionism on the relation between early maladaptive schemas and academic procrastination

Note: SE: Study for an exam; PT: Performing administrative tasks; FA: Failure; DI: dependence/incompetence; US: unrelenting standards/hypocriticalness.

The Sobel test was used to test the significance of the mediating effects of negative perfectionism.

Table 3. Sobel test for the mediational model

\begin{tabular}{llll}
\hline \multicolumn{2}{c}{ Model pathway } & Sobel test & P \\
\hline early maladaptive schemas $\longrightarrow$ & negative perfectionism & 2.43 & 0.007 \\
& $\longrightarrow$ academic procrastination & & \\
\hline
\end{tabular}

According to the results, negative perfectionism can mediate on the relationship between early maladaptive schemas and academic procrastination in students. Because P-value is smaller than $0.05(\mathrm{p}<0.05)$.

\section{Discussion}

The goal of the present study was to test the role of negative procrastination on the relationship between early maladaptive schemas and academic procrastination in Iranian students. Correlational analysis revealed that early maladaptive schemas, negative perfectionism were positively related to academic procrastination. These results are consistent with previous studies that conducted on the relationships between early maladaptive schemas, negative perfectionism, and academic procrastination (Renner, lobbestael, Peeters, Arntz, \& Huibers, 2012; Mojallal, Khosrojavid, Pakzad, \& Ghanbari, 2014; Zakeri, Esfahani, \& Razmjoee, 2013; Zakeri, Esfahani, \& Razmjoee, 2013; Jadidi, Mohammadkhani, \& Tajrishi, 2011). These relationships can be explained as follows: early maladaptive schemas can have a positive impact on the academic procrastination of individuals; the perfectionism of personal achievement will affect the level of individual academic procrastination, that is, higher negative perfectionism will lead to higher individual academic procrastination.

In accordance with our expectations, negative perfectionism partially mediated the association between early maladaptive schemas and academic procrastination. The path of early maladaptive schemas to Negative perfectionism, and Negative perfectionism to academic procrastination was significant. This path indicates that high level of early maladaptive schemas will often result in higher negative perfectionism tendencies and thus show a high level of academic procrastination. Because according to Young et al. (1950) individuals with unrelenting standards/Hypocriticalness schema believe that they do the tasks flawlessness, even this schema 
presents as perfectionism. Accordingly such believe, result in higher level of negative perfectionism in individuals. In other hand higher level of negative perfectionism tendencies lead to procrastination in the other words, academic procrastination is consequence of negative perfectionism. These two construct have a close relationship with together (Fiore, 2002).

To sum up, the present study provides substantial insight into a complicated interplay among early maladaptive schemas, academic procrastination, and perfectionism in Iranian students. These findings highlight a previously unidentified mechanism explaining the relation between maladaptive schemas and academic procrastination. The employment of Iranian participants provides evidence for external validity of among early maladaptive schemas, academic procrastination, and perfectionism. In consideration of the probable mechanisms, it provides valuable guidance on how to implement psychological interventions aimed at decrease individuals' academic procrastination. However, several important limitations of the present study must be considered. Firstly, the data in this study were collected only through self-report scales. One of the largest drawbacks of self-report measures lies in its failure to completely inhibit the effect of social desirability, as the subjects may more or less guess the intents of questions in the answering process, while the effect of social desirability will cause the subjects to choose the best option they consider, rather than the option truly in line with their actual conditions, resulting in decreased effectiveness of measurement. In addition, it is impossible for a good scale to accomplish perfect questions, so it is difficult to completely get rid of the errors arising from the effect of social desirability. The use of multiple methods for evaluation may reduce the impact of subjectivity. Secondly, the study relied on Iranian student sample, which limits the generalizability of the findings of the current study. Finally, the present study was a cross-sectional design. Thus, the findings described in this report reflect associations and predictions but not cause-effect relations between the variables. Therefore, for further studies, longitudinal and experimental studies would provide additional insights into relationships between early maladaptive schemas, academic procrastination, and perfectionism.

\section{References}

Burnam, A., Komarraju, M., Hamel, R., \& Nadler, D. R. (2014). Do adaptive perfectionism and self-determined motivation reduce academic procrastination? Learning and Individual Differences, 36, 165-172. https://doi.org/10.1016/j.lindif.2014.10.009

Çapan, B. E. (2010). Relationship among perfectionism, academic procrastination and life satisfaction of university students. Procedia-Social and Behavioral Sciences, 5, 1665-1671. https://doi.org/10.1016/j.sbspro.2010.07.342

Cukor, D., Coplan, J., Brown, C., Friedman, S., Cromwell-Smith, A., Peterson, R. A., \& Kimmel, P. L. (2007). Depression and anxiety in urban hemodialysis patients. Clinical Journal of the American Society of Nephrology, 2(3), 484-490. https://doi.org/10.2215/CJN.00040107

Egan, S. J., Wade, T. D., \& Shafran, R. (2011). Perfectionism as a transdiagnostic process: A clinical review. Clinical psychology review, 31(2), 203-212. https://doi.org/10.1016/j.cpr.2010.04.009

Ellis, A., \& Knaus, W. J. (1977). Overcoming procrastination. New York: Signet Books.

Fedewa, B. A., Burns, L. R., \& Gomez, A. A. (2005). Positive and negative perfectionism and the shame/guilt distinction: Adaptive and maladaptive characteristics. Personality and individual differences, 38(7), 1609-1619. https://doi.org/10.1016/j.paid.2004.09.026

Frost, R. O., Heimberg, R. G., Holt, C. S., Mattia, J. I., \& Neubauer, A. L. (1993). A comparison of two measures of perfectionism. Personality and individual differences, 14(1), 119-126. https://doi.org/10.1016/0191-8869(93)90181-2

Howell, A. J., Watson, D. C., Powell, R. A., \& Buro, K. (2006). Academic procrastination: The pattern and correlates of behavioural postponement. Personality and Individual Differences, 40(8), 1519-1530. https://doi.org/10.1016/j.paid.2005.11.023

Isanejad, O., Heidary, M. S., Rudbari, O., \& Liaghatdar, M. J. (2012). Early maladaptive schemes and academic anxiety. World Applied Sciences Journal, 18(1), 107-112.

Jadidi, F., Mohammadkhani, S., \& Tajrishi, K. Z. (2011). Perfectionism and academic procrastination. Procedia-Social and Behavioral Sciences, 30, 534-537. https://doi.org/10.1016/j.sbspro.2011.10.104

Kandemir, M., İlhan, T., Özpolat, A. R., \& Palanci, M. (2014). Analysis of academic self-efficacy, self-esteem and coping with stress skills predictive power on academic procrastination. Educational Research and Reviews, 9(5), 146. https://doi.org/10.5897/ERR2014.1763 
Karner-Huţuleac, A. (2014). Perfectionism and self-handicapping in adult education. Procedia-Social and Behavioral Sciences, 142, 434-438. https://doi.org/10.1016/j.sbspro.2014.07.699

Kıral, E. (2015). The Relationship between Locus of Control and Perfectionism Perception of the Primary School Administrators. Procedia-Social and Behavioral Sciences, 174, 3893-3902. https://doi.org/10.1016/j.sbspro.2015.01.1130

Komarraju, M., \& Nadler, D. (2013). Self-efficacy and academic achievement: Why do implicit beliefs, goals, and effort regulation matter? Learning and Individual Differences, 25, 67-72. https://doi.org/10.1016/j.lindif.2013.01.005

Li, Y., Lan, J., \& Ju, C. (2015). Achievement motivation and attributional style as mediators between perfectionism and subjective well-being in Chinese university students. Personality and Individual Differences, 79, 146-151. https://doi.org/10.1016/j.paid.2015.01.050

Lowinger, R. J., Kuo, B. C., Song, H. A., Mahadevan, L., Kim, E., Liao, K. Y. H., ... \& Han, S. (2016). Predictors of Academic Procrastination in Asian International College Students. Journal of Student Affairs Research and Practice, 53(1), 90-104. https://doi.org/10.1080/19496591.2016.1110036

Malinauskiene, O., Vosylis, R., \& Zukauskiene, R. (2011). Longitudinal examination of relationships between problem behaviors and academic achievement in young adolescents. Procedia-Social and Behavioral Sciences, 15, 3415-3421. https://doi.org/10.1016/j.sbspro.2011.04.311

Masoumeh Khosravi, M. A., \& Bahonar, M. (n.d.). Comparing early maladaptive schemas and coping styles in drug dependent and non-dependent prisoners of Zahedan city, Iran. Annals of Military and Health Sciences Research, 26.

Maurizi, L. K., Grogan-Kaylor, A., Granillo, M. T., \& Delva, J. (2013). The role of social relationships in the association between adolescents' depressive symptoms and academic achievement. Children and youth services review, 35(4), 618-625. https://doi.org/10.1016/j.childyouth.2013.01.006

Mojallal, M., Khosrojavid, M., Pakzad, F., \& Ghanbari, M. (2014). Early Maladaptive Schemas, Body Image, and Self-Esteem in Iranian Patients Undergone Cosmetic Surgery Compared with Normal Individuals. Practice in Clinical Psychology, 2(3), 201-210.

Odaci, H. (2011). Academic self-efficacy and academic procrastination as predictors of problematic internet use in university students. Computers \& Education, 57(1), 1109-1113. https://doi.org/10.1016/j.compedu.2011.01.005

Onwuegbuzie, A. J. (2004). Academic procrastination and statistics anxiety. Assessment \& Evaluation in Higher Education, 29(1), 3-19. https://doi.org/10.1080/0260293042000160384

Renner, F., Lobbestael, J., Peeters, F., Arntz, A., \& Huibers, M. (2012). Early maladaptive schemas in depressed patients: Stability and relation with depressive symptoms over the course of treatment. Journal of affective disorders, 136(3), 581-590. https://doi.org/10.1016/j.jad.2011.10.027

Schouwenburg, H. C., Lay, C. H., Pychyl, T. A., \& Ferrari, J. R. (2004). Counseling the procrastinator in academic settings. American Psychological Association. https://doi.org/10.1037/10808-000

Trucchia, S. M., Lucchese, M. S., Ender, J. E., \& Fernández, A. R. (2013). Relationship between academic performance, psychological well-being, and coping strategies in medical students. Herramientas, 70(3).

Weidman, A. C., Augustine, A. A., Murayama, K., \& Elliot, A. J. (2015). Internalizing symptomatology and academic achievement: Bi-directional prospective relations in adolescence. Journal of Research in Personality, 58, 106-114. https://doi.org/10.1016/j.jrp.2015.07.005

Zakeri, H., Esfahani, B. N., \& Razmjoee, M. (2013). Parenting styles and academic procrastination. Procedia-Social and Behavioral Sciences, 84, 57-60. https://doi.org/10.1016/j.sbspro.2013.06.509

\section{Copyrights}

Copyright for this article is retained by the author(s), with first publication rights granted to the journal.

This is an open-access article distributed under the terms and conditions of the Creative Commons Attribution license (http://creativecommons.org/licenses/by/4.0/). 